\title{
Vacina experimental produzida em cultivo celular confere proteção parcial contra o ectima contagioso em ovinos ${ }^{1}$
}

\author{
Candice Schmidt ${ }^{2}$, Juliana Felipetto Cargnelutti², Mathias Martins ${ }^{2}$, Rudi Weiblen ${ }^{2}$ \\ e Eduardo Furtado Flores ${ }^{2 *}$
}

\begin{abstract}
Schmidt C., Cargnelutti J.F., Martins M., Weiblen R. \& Flores E.F. 2012. [Experimental vaccine produced in tissue culture confers partial protection against contagious ecthyma in sheep.] Vacina experimental produzida em cultivo celular confere proteção parcial contra o ectima contagioso em ovinos. Pesquisa Veterinária Brasileira 32(1):11-16. Setor de Virologia, Departamento de Medicina Veterinária Preventiva, Centro de Ciências Rurais, Universidade Federal de Santa Maria, Av. Roraima 1000, Camobi, Santa Maria, RS 97105-900, Brazil. E-mail: eduardofurtadoflores@gmail.com

Contagious ecthyma, also known as orf, is a debilitating disease of sheep and goats caused by the parapoxvirus, orf virus (ORFV). Vaccination has been used with relative success to reduce the losses caused by the disease, yet the current vaccines contain virulent virus, are empirically produced through skin scarification of live lambs, and present questionable efficacy. Therefore, the present study aimed at developing and testing an experimental ORFV vaccine produced in tissue culture. The ORFV strain IA-82 was submitted to 21 passages in BHK-21 cells and then used to immunize lambs $(n=30)$ through skin scarification of the internal face of the hind limb. Vaccination produced localized pustules and scabs lesions in 16 out of 30 animals, indicating an adequate replication of the vaccine virus. $\mathrm{Ni}$ nety days after vaccination, vaccinated $(\mathrm{n}=16)$ and control lambs $(\mathrm{n}=16)$ were inoculated with a virulent $\mathrm{ORFV}$ strain $\left(10_{6,9} \mathrm{TCID}_{50} / \mathrm{ml}\right)$ in the labial commissure. Vaccinated and control lambs developed typical orf lesions, characterized by hyperemia, vesicles, pustules and scab formation. Nonetheless, vaccinated animals developed milder lesions compared to controls and the clinical scores were significantly lower $(\mathrm{p}<0.05)$ between days 10 and 22 post-challenge. In addition, the mean duration of clinical disease was significantly reduced in vaccinated animals $(p<0.05)$. Furthermore, vaccinated animals excreted much less virus $(\mathrm{p}<0.05)$ and for a significantly shorter period of time than did the controls (13 days versus 22 days, $p<0.001$ ). These results demonstrate partial protection by the experimental vaccine and, upon improvement of immunization and protection indices, are promising towards the use of tissue culture-based ORFV vaccines.
\end{abstract}

INDEX TERMS: Contagious ecthyma, orf, sheep, vaccine, tissue culture.

RESUMO.- 0 ectima contagioso (também conhecido como orf), é uma doença debilitante de ovinos e caprinos causada pelo vírus do orf (ORFV). A vacinação tem sido usada com relativo sucesso no controle da doença. No entanto, as vacinas atuais contêm amostras virulentas do agente, são produzidas por escarificação cutânea de animais, e apresentam eficácia questionável. Assim, o presente trabalho teve como

\footnotetext{
${ }^{1}$ Recebido em 18 de julho de 2011

Aceito para publicação em 13 de setembro de 2011.

${ }^{2}$ Setor de Virologia, Departamento de Medicina Veterinária Preventiva (DMVP), Centro de Ciências Rurais (CCR), Universidade Federal de Santa Maria (UFSM), Santa Maria, RS 97105-900. Brasil. *Autor para correspondência: eduardofurtadoflores@gmail.com
}

objetivo produzir e testar a eficácia de uma vacina experimental produzida em cultivo celular. A cepa IA-82 do ORFV foi submetida a 21 passagens em cultivo de células BHK-21 e usada para vacinar ovinos jovens $(n=30)$, por escarificação cutânea na face interna da coxa. A vacinação produziu pústulas e crostas em 16 dos 30 ovinos vacinados, indicando imunização adequada. Noventa dias após a vacinação, ovinos vacinados $(n=16)$ e controles $(n=16)$ foram inoculados com uma cepa virulenta do ORFV $\left(10^{6,9} \mathrm{DICC}_{50} / \mathrm{mL}\right)$ após escarificação na comissura labial. Todos os animais desenvolveram lesões típicas de ectima, incluindo hiperemia, vesículas, pústulas e crostas. No entanto, os animais vacinados desenvolveram lesões mais leves e passageiras 
do que os controles, e os escores clínicos foram estatisticamente diferentes $(p<0,05)$ entre os dias 10 e 22 pós-desafio. Além disso, o tempo de duração da doença foi significativamente inferior $(p<0,05)$ nos animais vacinados. Os animais vacinados também excretaram menor quantidade de vírus $(p<0,05)$ e por um período significativamente mais curto do que os controles (13 dias versus 22 dias, $p<0,001$ ). Esses resultados demonstram a proteção parcial conferida pela vacina experimental e, dependendo da melhoria dos índices de imunização e proteção, são promissores no sentido da utilização de vacinas contra o ORFV produzidas em cultivo celular.

TERMOS DE INDEXAÇÃO: Ectima contagioso, orf, ovinos, vacina, cultivo celular.

\section{INTRODUÇÃO}

O ectima contagioso, também conhecido como "orf" (do inglês: aspecto rugoso), estomatite pustular contagiosa ou dermatite pustular contagiosa, é uma enfermidade debilitante de ovinos e caprinos, e que ocasionalmente acomete o homem (Haig \& Mercer 1998). A doença é causada pelo vírus do orf (ORFV), um vírus DNA, pertencente ao gênero Parapoxvirus, da família Poxviridae (Hosmarini et al. 2009). O ORFV possui distribuição mundial, e afeta principalmente ovinos e caprinos jovens, nos quais produz lesões inflamatórias proliferativas ao redor da boca e das narinas (Haig 2006). As lesões são progressivas e debilitantes, reduzindo a capacidade dos animais se alimentarem (Haig 2006, Fleming \& Mercer 2007). Embora a mortalidade seja relativamente baixa, a ocorrência da infecção em um rebanho afetado pode chegar a $90 \%$. A disseminação da infecção dentro do rebanho é rápida e pode ocorrer pelo contato direto entre animais ou pelo contato com crostas das lesões que ficam no ambiente (Fleming \& Mercer 2007).

Em geral, as lesões da infecção pelo ORFV são confinadas ao epitélio dos lábios, narinas e mucosa oral (Haig 2006). Animais lactentes podem transmitir o vírus para os tetos e úbere de suas mães durante a amamentação, acarretando no desenvolvimento de lesões mamárias, e da mesma forma, animais que possuem lesões nos tetos podem transmitir o vírus para os cordeiros que estão sendo amamentados (Fleming \& Mercer 2007). Após penetrar por abrasões na pele, junção mucocutânea dos lábios ou mucosa oral (Fleming \& Mercer 2007), o vírus replica localmente nos queratinócitos em regeneração da epiderme (McKeever et al. 1988). 0 período de incubação da doença varia entre dois e seis dias, e as lesões progridem pelos estádios de eritema, máculas, pápulas, vesículas, pústulas e crostas (Haig 2006, Fleming \& Mercer 2007). As lesões crostosas são proliferativas e, frequentemente, apresentam rachaduras e sangramento, podendo predispor a infecções secundárias e miíases (Haig 2006, Fleming \& Mercer 2007). A resolução das lesões nas infecções primárias, geralmente ocorre em quatro a seis semanas, enquanto que em re-infecções a resolução é mais rápida (Haig 2006, Fleming \& Mercer 2007). Não existem evidências de disseminação sistêmica desse vírus (Haig 2006).

O ectima contagioso está amplamente difundido nos rebanhos ovino e caprinos do Brasil, e vários relatos têm sido publicados, alguns com comprometimento humano (Salles et al. 1992, Nóbrega Jr et al. 2008). Há relatos de surtos em rebanhos de ovinos no Rio Grande do Sul (Salles et al. 1992), em São Paulo (Langoni et al. 1995, Catroxo et al. 2002), e na Paraíba, onde houve envolvimento de ovinos, caprinos e humanos (Nóbrega Jr et al. 2008). No nordeste, desde a década de 30 , a enfermidade é um dos principais problemas sanitários da exploração caprina, por acometer cerca de 60\% das criações (Torres 1939).

Embora não confira proteção clínica completa, a vacinação tem sido utilizada com relativo sucesso no controle da doença em vários países. A dificuldade de se obter proteção completa deve-se a capacidade do vírus de re-infectar os seus hospedeiros, apesar da resposta à infecção (Haig 2006, Fleming \& Mercer 2007). Diferentes tipos de vacinas contra o ORFV já foram produzidas, mas a vacina que contém o vírus replicativo, sem prévia atenuação, ainda é a mais utilizada em vários países (Nandi et al. 2011), inclusive no Brasil (Canal 2007). Essa vacina é produzida à partir de crostas infectivas, coletadas de animais previamente escarificados e inoculados com ORFV virulento. No entanto, este método apresenta várias restrições que limitam a sua aceitação, incluindo: (i) método cruento de produção, envolvendo uso de animais; (ii) possibilidade de contaminantes na vacina (Buddle et al. 1984); (iii) dificuldade de obtenção de doses em grande escala; (iv) virulência do vírus vacinal, que pode causar a doença quando transmitido pelos animais vacinados (Musser et al. 2008). Vacinas com o vírus amplificado em cultivo celular têm sido desenvolvidas e utilizadas como alternativa (Pye 1990, Nettleton et al. 1996). Algumas dessas vacinas têm se mostrado relativamente eficazes e seguras, produzem apenas lesões brandas após escarificação, e promovem imunidade por aproximadamente 4 a 6 meses (Nettleton et al. 1996, Hosmarini e al. 2009). No entanto, a eficácia das vacinas contra o ectima contagioso, em especial aquelas produzidas em cultivo celular, ainda é questionada (Buddle et al. 1984).

Já foi demonstrado que o ORFV pode ser adaptado a replicar em vários tipos de células, incluindo células de pele de embriões de ovino (Greig 1956), em cultivos primários de testículo ovino (Buddle et al. 1984, Pye 1990), de rim e pulmão ovino (Pye 1990), de corneto etmoidal ovino (Delhon et al. 2004) e de linhagem de rim fetal ovino (Musser et al. 2008), entre outras. Assim, esse trabalho teve como objetivos adaptar a cepa IA-82 do ORFV em células BHK21 (Baby Hamster Kidney) e, subsequentemente, avaliar a proteção conferida pela imunização de ovinos com o vírus produzido em cultivo celular, frente a desafio com um isolado virulento de campo.

\section{MATERIAL E MÉTODOS}

Desenho experimental. Foram utilizados 46 ovinos, machos e fêmeas, das raças Ideal e Corriedale, com idade entre três e quatro meses, provenientes de uma propriedade sem histórico clínico de ectima contagioso há pelo menos oito anos. Inicialmente, 30 animais foram imunizados pela via intradérmica com a vacina experimental. A reação vacinal foi avaliada 10 dias após, e apenas os animais que apresentaram reação vacinal local foram incluídos na segunda fase do experimento. Estes animais (G1=16), e outros 16 controles não-vacinados (G2) foram desafiados por escarificação da comissura 
labial seguida da inoculação com um isolado de campo de ORFV, 90 dias após a vacinação. Após o desafio, realizou-se a avaliação clínica e coleta de suabes para isolamento e quantificação viral.

Células e vírus. Células de linhagem BHK-21 foram utilizadas para a amplificação do vírus vacinal. Células primárias de corneto etmoidal ovino (CEO) foram utilizadas para isolamento e quantificação viral a partir das lesões. As células foram cultivadas em meio essencial mínimo (MEM), contendo penicilina (1,6 mg/l), estreptomicina $(0,4 \mathrm{mg} / \mathrm{l})$, anfotericina $B(2,25 \mathrm{mg} / \mathrm{l})$, e suplementadas com $10 \%$ de soro fetal bovino (SFB). A cepa IA-82 foi utilizada como vírus vacinal. Esta cepa foi isolada de secreções nasais de um ovino com ectima contagioso no estado de Iowa, EUA em 1982 e cedida pelo Dr. Daniel Rock (College of Veterinary Medicine, University of Illinois, Urbana-Champaign, USA). As crostas utilizadas para o desafio foram coletadas de um surto de ectima em um rebanho ovino no município de Canguçu, no Rio Grande do Sul.

Vacina experimental e imunização. A cepa ORFV IA-82 foi adaptada por 21 passagens em células BHK-21. Os cultivos infectados (passagem 21), foram então submetidos a três ciclos de congelamento e descongelamento, centrifugados e o sobrenadante foi utilizado como vacina. 0 inóculo vacinal continha um título de $10^{6} \mathrm{DICC}_{50} / \mathrm{ml}$ (doses infectantes para $50 \%$ dos cultivos celulares). Inicialmente, 30 ovinos foram inoculados na parte interna da coxa, após escarificação cutânea em uma área aproximada de $2 \times 2 \mathrm{~cm}$, com $200 \mu \mathrm{l}$ do vírus vacinal. Para a escarificação, utilizou-se um dispositivo metálico comercializado com as vacinas comerciais. Dez dias após a imunização, os animais foram examinados para investigar as lesões resultantes da inoculação, denominadas empiricamente de "pega". Os animais que não desenvolveram lesão vacinal foram excluídos do experimento. Somente os animais que apresentaram lesões sugestivas de replicação viral após a vacinação $(n=16)$ foram incluídos no restante do estudo, constituindo o grupo vacinado (G1). Outros 16 animais, não vacinados, permaneceram como grupo controle (G2). Noventa dias após a vacinação, os animais de ambos os grupos (G1 e G2) foram desafiados pela inoculação de um isolado de campo na comissura labial.

Desafio e monitoramento clínico. Para o desafio, foram utilizadas crostas de ectima contagioso provenientes de um surto ocorrido em Canguçu, no RS. As crostas foram maceradas e ressuspendidas em MEM na proporção de 1:5 peso/volume. Após centrifugação a $2.500 \mathrm{rpm}$ por 7 min coletou-se o sobrenadante, que foi titulado em células CEO e utilizado com inóculo. 0 vírus do desafio $(400 \mu \mathrm{l}$ da suspensão de crostas) foi inoculado na junção mucocutânea da comissura labial após escarificação com agulha hipodérmica (título de $10^{6,9} \mathrm{DICC}_{50} / \mathrm{ml}$ ).

Após o desafio, os animais foram monitorados durante 28 dias, em relação a aspectos clínicos e virológicos. 0 monitoramento clínico foi realizado por inspeção visual minuciosa das áreas de inoculação viral. Para tornar a avaliação clínica objetiva, estabeleceu-se um escore clínico para cada sinal observado. Os critérios utilizados foram os seguintes: hiperemia: ausência (-); hiperemia leve (+); hiperemia moderada $(++)$; hiperemia severa $(+++)$. Vesículas e/ ou pústulas: ausência (-); pequeno número (+); número moderado $(++)$; grande número $(+++)$. Crostas: ausência $(-)$; pequeno número (+); número moderado $(++)$; grande número $(+++)$. Exsudação e sangramento: ausência (-); presença (+). Miíase: ausência (-); presença (+). A metodologia para calcular o escore clínico foi adaptada de Nettleton et al. (1996). 0 escore clínico diário de cada grupo foi obtido pela média aritmética dos escores individuais.

Monitoramento virológico. Suabes coletados das lesões a cada dois dias foram submetidos a isolamento e quantificação de vírus. Os suabes foram drenados, centrifugados em baixa rotação, e o sobrenadante foi inoculado em placas de 24 cavidades contendo células CEO e submetidos à três passagens de cinco dias cada. Para a quantificação de vírus excretado, foram processadas aleatoriamente 10 amostras, sendo cinco amostras do grupo vacinado e cinco do grupo controle, para os dias 6, 10, 12 e 14 pd. Essas amostras foram submetidas à quantificação viral pelo método de diluição limitante. A leitura das placas foi feita com seis dias e os títulos virais foram calculados de acordo com Reed \& Muench (1938) e expressos em $\log _{10}$ DICC $_{50} / \mathrm{ml}$.

Análise estatística. As diferenças entre os escores clínicos diários observados para cada grupo foram comparadas pela Análise de Variância (ANOVA), seguido do Teste de Tukey que foi utilizado como post hoc. Os valores dos títulos virais em escala logarítmica foram submetidos à transformação para atender os pré-requisitos do teste e submetidos à Análise de Variância (ANOVA), seguido de Teste de Tukey. 0 tempo de excreção viral dos dois grupos foi comparado pelo Teste t de Student's. Todas as análises foram realizadas utilizando-se o programa GraphPad Prism 5.

\section{RESULTADOS}

Adaptação da cepa IA-82 em células BHK-21. 0 efeito citopático de ORFV foi inicialmente observado após a 5 a passagem da cepa IA-82 em células BHK-21. No entanto, os títulos virais obtidos durante a adaptação se mantiveram baixos durante diversas passagens, sendo que apenas na passagem 21 obteve-se um título viral de $10^{6}$, possibilitando assim o seu uso como antígeno vacinal.

Reação vacinal. Dezesseis animais vacinados $(16 / 30)$ apresentaram lesões no sítio de vacinação, quando examinados 10 dias após, e foram mantidos no experimento. As lesões eram leves, restritas e caracterizavam-se por hiperemia local, pústulas coalescentes e discreta formação de crostas. Os 14 animais que não apresentaram lesão vacinal foram excluídos do estudo.

Monitoramento clínico pós-desafio. Após o desafio, os 32 animais inoculados na comissura labial desenvolveram lesões características de ectima contagioso. Na maioria dos animais, as lesões iniciaram ao redor do dia 4 pós-desafio (pd), caracterizando-se por hiperemia na região da escarificação, formação inicial de pápulas e vesículas no sítio de inoculação. Em geral, as lesões dos animais vacinados foram notavelmente mais brandas e regrediram mais rapidamente (Fig.1 e Fig.2). Até o dia 8 pd, os sinais observados no sítio de inoculação e a média do escore clínico diário total se mantiveram semelhantes nos dois grupos (Fig.2). A partir do dia 10 pd, no entanto, as lesões no grupo vacinado (G1) apresentaram uma rápida regressão, comparando-se com os animais do grupo controle (G2), que nesse dia apresentavam intensa exsudação e sangramento das lesões (Fig.1A,B). Além disso, a partir do dia 12 pd alguns animais controle desenvolveram miíases e infecção secundária nas lesões. Entre os dias 10 pd e 22 pd, as médias diárias do escore clínico total diferiram significativamente $(\mathrm{P}<0,05)$ entre os dois grupos (Fig.2). A partir do dia 20 pd, as lesões haviam praticamente cicatrizado nos animais vacinados, mas mantiveram-se além do dia 28 em parte dos controles (Fig.2). Em resumo, tanto os animais vacinados quanto os controles desenvolveram lesões nos locais de inoculação viral, porém a severidade e duração das lesões foram notadamente inferiores nos animais vacinados.

Monitoramento virológico pós-desafio. Todos os animais desafiados excretaram o vírus nas lesões desenvolvidas na comissura labial, por períodos variáveis. Porém, os 


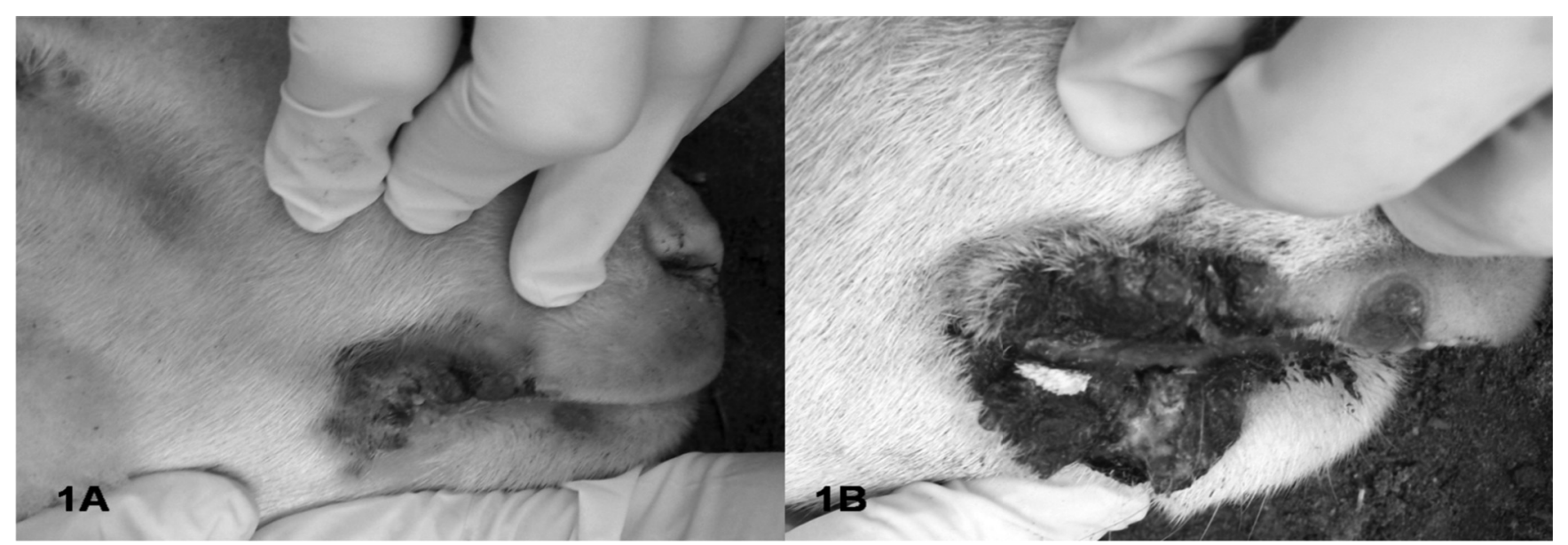

Fig.1. Lesões na comissura labial de ovinos desafiados com uma amostra virulenta do ORFV. (A) Ovino vacinado apresentando lesão com hiperemia e intensidade moderada de crostas, 10 dias após o desafio. (B) Ovino controle, apresentando intensa formação de lesões crostosas, com rachaduras, exsudação e ovos de Cochliomyia hominivorax, 10 dias após o desafio.

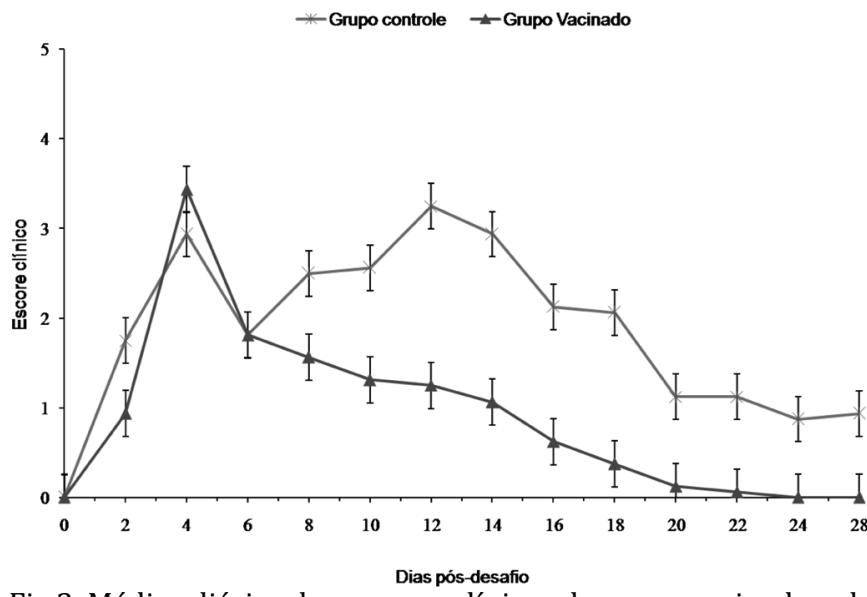

Fig.2. Médias diárias dos escores clínicos do grupo vacinado e do grupo controle após o desafio com um isolado virulento do ORFV, 90 dias após a vacinação. As médias do grupo controle foram significativamente mais altas que as do grupo vacinado entre os dias 10 e 22 pós-desafio. As barras verticais demonstram o erro padrão entre as médias.

animais do grupo vacinado apresentaram um período médio de excreção de 13,4 dias $\pm 0,4$ (média \pm erro padrão) que foi significativamente inferior $(\mathrm{P}<0,001)$ ao do grupo controle que, em média, excretou vírus por 22,6 dias $\pm 1,0$. As médias dos títulos virais excretados nos dias 6,10,12 e 14 pelos animais vacinados também foram significativamente inferiores $(\mathrm{P}<0,05)$ às médias excretadas pelo grupo controle (Fig.3), com maior diferença observada no dia 10 pd $(\mathrm{P}<0,001)$. Além disso, os animais vacinados cessaram a excreção viral vários dias antes dos controles (Fig.4). Enquanto no dia 14 pd todos os animais (G1 e G2) ainda excretavam vírus, o número de animais vacinados excretando vírus foi se reduzindo rapidamente a partir do dia $16 \mathrm{pd}$, e a excreção viral cessou a partir do dia 22 pd (Fig.4). Já no grupo controle, nove animais ainda permaneciam excretando vírus no dia 28 pd, quando o experimento foi descontinuado. Esses resultados demonstram que a vacinação reduziu significativamente o tempo de excreção viral e, na maior parte do período, os títulos virais excretados.

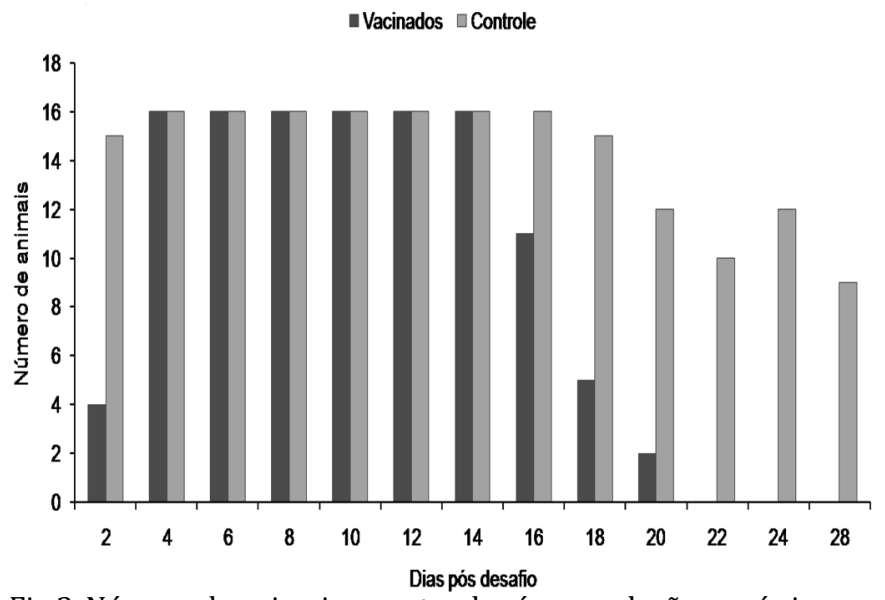

Fig.3. Número de animais excretando vírus nas lesões, após inoculação com uma amostra virulenta do ORFV

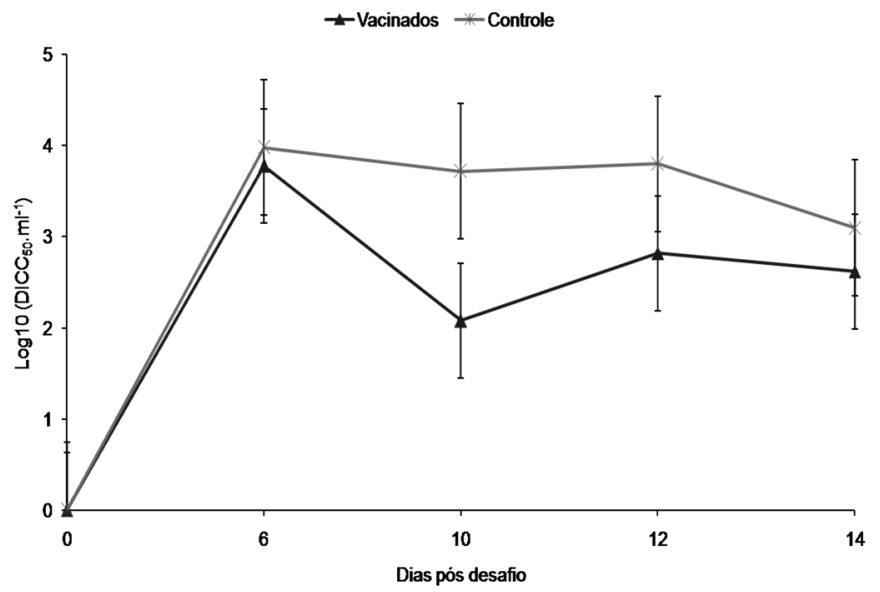

Fig.4. Títulos virais médios detectados nas lesões da comissura labial de animais inoculados com uma amostra virulenta do ORFV.

\section{DISCUSSÃO}

As vacinas contra o ectima contagioso comercializadas no Brasil, a exemplo de outros países que possuem ovinocultura e caprinocultura desenvolvidas, são produzidas em 
animais, por métodos empíricos e cruentos, possuem vírus virulento em sua formulação e apresentam eficácia questionável. Por outro lado, a grande população ovina e caprina no país (aproximadamente 17 e 9 milhões de cabeças, respectivamente (IBGE 2010)) aliada com a ampla disseminação da doença e os prejuízos que causa, justificam o interesse por vacinas eficazes, seguras e produzidas sem o uso de animais e por métodos eticamente aceitáveis. Dessa forma, uma vacina experimental foi produzida em cultivo celular e a sua eficácia foi testada em ovinos. Embora a proteção conferida tenha sido parcial (a exemplo das vacinas comerciais), os resultados são promissores, desde que os índices de imunização ("pega") e proteção possam ser melhorados.

As vacinas tradicionais contra o ectima contagioso são produzidas a partir de crostas obtidas após escarificação cutânea de ovinos com isolados virulentos do ORFV, e são aplicadas também por escarificação cutânea, geralmente na face interna do membro anterior ou posterior, para evitar a disseminação do vírus por contato. Essas vacinas apresentam restrições, que incluem questões éticas, de segurança (vírus vacinais virulentos que podem ser transmitidos e causar doença), risco de agentes contaminantes, além da dificuldade de padronização e produção em escala industrial. Para contornar esses problemas, vacinas produzidas em cultivo celular têm sido propostas e desenvolvidas, algumas com relativo sucesso (Pye 1990, Nettleton et al. 1996). No entanto, a maior restrição às vacinas contra o ectima - e que se aplica tanto às tradicionais quanto às produzidas em cultivo celular - refere-se à falha em induzir proteção completa frente a exposição ao vírus de campo. As vacinas produzidas a partir de crostas de animais escarificados parecem ser mais imunogênicas (Buddle et al. 1984), porém a proteção conferida pelos dois tipos de vacina é geralmente parcial e incompleta, em diferentes níveis (Buddle et al. 1984, Pye 1990, Nettleton et al. 1996, Musser et al. 2008). Assim, na maioria dos relatos, uma parcela variável dos animais vacinados desenvolve sinais clínicos de ectima quando é desafiada com amostras de campo, embora esses sinais sejam usualmente mais brandos e passageiros (Buddle et al. 1984, Musser et al. 2008). As causas dessa proteção parcial e incompleta são pouco conhecidas, mas aparentemente não incluem eventuais diferenças antigênicas entre o vírus vacinal e o vírus do desafio (Buddle et al. 1984, Glover 1928).

A imunidade induzida após infecções naturais ou experimentais pelo ORFV é parcial e temporária. Dessa forma, o vírus possui a capacidade de re-infectar os seus hospedeiros e produzir lesões, que são geralmente mais leves e transitórias do que na infecção primária (de La Concha-Bermejillo et al. 1999, Haig et al. 2002). Assim, é possível que a falha em conferir proteção completa possa estar mais relacionada com peculiaridades das interações do vírus com o sistema imunológico do que com deficiências intrínsecas das vacinas.

No presente trabalho, a aplicação da cepa IA-82 por escarificação cutânea produziu lesões locais - observadas no dia 10 pós-vacinação - em 16 de 30 animais. A resposta local à vacinação (hiperemia, pústulas e crostas) tem sido adotada como indicador da replicação viral e, consequen- temente, da eficácia da imunização (Buddle et al. 1984, Pye 1990, Nettleton et al. 1996, Musser et al. 2008). Embora o índice de "pega" das vacinas utilizadas a campo seja desconhecido e difícil de estimar, a frequência, intensidade e duração dos sinais pós-vacinais relatados em estudos experimentais tem sido, em geral, superiores aos observados no presente trabalho (Buddle et al. 1984, Pye 1990, Nettleton et al. 1996, Musser et al. 2008). É provável que a adaptação da cepa IA-82 ao cultivo de células BHK-21 durante 21 passagens tenha resultado em atenuação excessiva do vírus. Além de variar entre isolados (de La Concha-Bermedillo et al. 2003, Musser et al. 2008), a capacidade imunogênica do ORFV está diretamente relacionada com a eficiência de replicação e capacidade de causar lesões nos sítios de inoculação (Pye 1990, Bundlle et al. 1996, Guo et al. 2003). Assim, vírus com fins vacinais amplificados em cultivo celular frequentemente apresentam capacidade reduzida de replicar em animais, produzem lesões mais leves e passageiras e, como consequência, são menos imunogênicos do que os vírus obtidos diretamente de crostas de animais doentes (Buddle et al. 1984). Por essas razões, os ORFV amplificados em cultivo celular com fins vacinais são submetidos a um número baixo de passagens (geralmente entre 2 e 3), provavelmente para evitar atenuação excessiva e redução da capacidade replicativa em animais (Pye 1990, Nettleton et al. 1996, Musser et al. 2008). Não obstante, alguns isolados de campo, mesmo submetidos a passagens em cultivo, podem apresentar capacidade replicativa in vivo e potencial imunogênico em níveis similares aos vírus obtidos de crostas (Pye 1990). Essas observações têm servido de premissa para o desenvolvimento e utilização de vacinas produzidas em cultivo (Pye 1990, Musser et al. 2008). No presente caso, para solucionar o problema da eficiência replicativa in vivo e baixa imunogenicidade da cepa IA-82, pretende-se testar diferentes isolados do ORFV em relação a capacidade replicativa e imunogênica em animais, após um número mínimo de passagens em cultivo celular.

A imunidade protetora contra o ORFV é geralmente de curta duração e decresce gradualmente ao longo dos meses (Haig \& McInnes 2002, de La Concha-Bermedillo et al. 2003). Os animais jovens são mais susceptíveis a desenvolverem doença grave, e a sua resistência aumenta gradualmente com a idade e com a exposição ao agente (Haig et al. 2002, de La Concha-Bermedillo et al. 2003). Por isso, em rebanhos endêmicos, a vacinação concentra-se nos animais jovens, com revacinações anuais dos animais introduzidos ou nascidos na próxima estação de reprodução (Musser et al. 2008). Por outro lado, as lesões da vacinação podem persistir por 28-35 dias (Buddle et al. 1984, Nettleton et al. 1996). Considerando-se esses aspectos, experimentos de proteção vacinal devem utilizar animais jovens, e o desafio não deveria ser realizado antes dos 3 ou 4 meses após a vacinação, como tem sido realizado em alguns trabalhos (Buddle et al. 1984, Pye 1990). No presente trabalho foram utilizados ovinos jovens (90-120 dias de idade), e o desafio foi realizado com intervalo de três meses, como descrito em alguns trabalhos (Nettleton et al. 1996, Musser et al. 2008).

0 presente experimento utilizou uma metodologia diferente dos demais trabalhos para o desafio. A exemplo dos 
estudos anteriores, realizou-se o desafio com macerado de crostas de animais doentes - supostamente associados com isolados virulentos de ORFV (Buddle et al. 1984, Pye 1990, Nettleton et al. 1996, Musser et al. 2008). No entanto, neste trabalho o vírus foi aplicado na junção mucocutânea da comissura labial, após escarificação com agulha hipodérmica, enquanto que os outros estudos realizaram o desafio pela inoculação do vírus após escarificação da pele do membro contralateral ao membro vacinado. Tem sido sugerido que a superfície cutânea escarificada da axila, focinho, lábios e bochecha apresenta susceptibilidade equivalente ao ORFV (Buddle et al. 1984). No entanto, a principal porta de entrada do vírus em infecções naturais são os lábios, comissuras labiais e focinho, e a penetração do vírus é facilitada por abrasões e microlesões causadas pela alimentação em pastagens grosseiras (Haig 2006, Fleming \& Mercer 2007). Assim, o procedimento de desafio adotado no presente experimento parece mais rigoroso para avaliar proteção do que inoculação em linhas de escarificação na pele da coxa. Não obstante, os próximos experimentos deverão utilizar desafio natural, pela exposição continuada dos animais vacinados (e controles) a animais deliberadamente infectados com vírus virulento. Dessa forma, se poderá avaliar de forma mais realista o nível de proteção à infecção natural, mimetizando o que ocorre a campo.

Outro aspecto único do presente trabalho foi a mensuração quantitativa e temporal da excreção viral após o desafio. Embora possa possuir importância menor em relação à proteção clínica, a redução significativa da quantidade e tempo de excreção viral pelos animais pode ter um impacto importante na transmissão do vírus em rebanhos, resultando em reduzida contaminação de animais e das pastagens e, consequentemente, reduzindo a disseminação do vírus no rebanho.

Em resumo, os resultados do presente estudo são promissores no sentido da produção em cultivo celular de uma vacina eficaz e segura contra o ectima contagioso. No entanto, várias etapas devem ser revistas para atingir tal objetivo, incluindo: (1) avaliar isolados de campo com relação à sua capacidade replicativa em cultivo celular; (2) avaliar isolados com relação à capacidade de replicar em animais após imunização, e de conferir proteção frente a desafio; (3) utilizar para vacinação amostras virais submetidas a um número menor de passagens em cultivo celular, para evitar atenuação excessiva; (4) aperfeiçoar o método de imunização, para permitir uma replicação cutânea mais eficiente do vírus vacinal; e (5) Alterar o método de desafio, para melhor mimetizar a exposição natural ao vírus e, assim, objetivamente avaliar o nível de proteção ao qual os animais vacinados estarão submetidos.

\section{REFERÊNCIAS}

Buddle B.M., Dellers, R.W. \& Schuring G.G. 1984. Contagious ecthyma virus-vaccination failures. Am. J. Vet. Res. 45:263-269.
Canal C.W. 2007. Poxviridae, p.489-510. In: Flores E.F. (Ed.), Virologia Veterinária. Vol.1. $2^{\text {nd }}$ ed. Editora UFSM, Santa Maria. 888p.

Catroxo M.H.B., Curi N.A., Pituco E.M., Garcia M., Okuda L.H., Porto A.C.R. \& Stefano E. 2002. Ocorrência de ectima contagioso em ovinos criados em Itatiba, estado de São Paulo, Brasil. Arqs Inst. Biológico, São Paulo, 69(Supl.):37.

De La Concha-Bermejillo A., Guo J., Zhang Z. \& Waldro D. 2003. Severe persistent orf in young goats. J. Vet. Diagn. Invest. 15:423-431.

Delhon G., Tulman, E.R., Afonso, C.L., Lu Z., La Concha-Bermejillo A., Lehmkuhl H.D., Piccone M.E., Kutish G.F. \& Rock D.L. 2004. Genomes of the parapoxviruses orf virus and bovine papular stomatitis virus. J. Virol. 78:168-177.

Fleming S.B. \& Mercer A.A. 2007 Genus Parapoxvirus, p.127-166. In: Mercer A.A. (Ed.), Poxviruses. Vol.1. Birkauser, Berlin. 441p.

Glover R.E. 1928. Contagious pustular dermatitis of the sheep. J. Comp. Pathol. 41:318-340.

Greig A.S. 1956. Contagious ecthyma of sheep: Attempts to infect other hosts. Can. J. Comp. Med. Vet. Sci. 20:448-452.

Guo J., Zhang Z., Edwards J.F., Ermel R.W., Taylor C.Jr \& La Concha-Bermejillo A. 2003. Characterization of a North American orf virus isolated from a goat with persistent, proliferative dermatitis. Virus Res. 93:169179.

Haig D. M. \& Mercer A. A. 1998. Ovine diseases: Orf. Vet. Res. 29:311-326.

Haig D.M. \& McInnes C.J., 2002. Immunity and counter immunity during infection with the parapoxvirus orf virus. Virus Res. 88:3-16.

Haig D.M. 2006. Orf virus infection and host immunity. Curr. Opin. Infect. Dis. 19:127-131.

Hosmarini M., Scagliarini A., Bhanuprakash V., McInnes C.J. \& Singh R.K. 2009. Orf: an update on current research an future perspectives. Expert Review of Anti-infective Therapy 7:879-893.

IBGE 2010. Instituto Brasileiro de Geografia e Estatística. Disponível em <http://www.ibge.gov.br/home/presidencia/noticias/noticia_impressao.php?id_noticia=1761> Acesso em 28 jun. 2011.

Langoni H., Coelho K.I.R., Pimentel M.P., Siqueira E.R. \& Spago E.N. 1995. Ectima contagioso em ovinos na região de Botucatu. Hora Vet., Porto Alegre, 14:60-62.

McKeever D.J. 1988. Studies of the pathogenesis of orf virus infection in sheep. J. Comp. Pathol. 99:318-327.

Musser J.M.B., Taylor C.A., Guo J., Tizard I.R. \& Walker J.W. 2008. Development of a contagious ecthyma vaccine for goats. Am. J. Vet. Res. 69:13661370.

Nandi S., Ujjwal K. \& Chowdhury S. 2011. Current status of contagious ecthyma or orf disease in goat and sheep: A global perspective. Small Rum. Res. 96:73-82.

Nettleton P.F., Brebner J., Pow J., Gilray J.A., Bell G.D. \& Reid H.W. 1996. Tissue culture-propagated orf virus vaccine protects lambs from orf virus challenge. Vet. Res. 138:184-186.

Nóbrega Jr, J.E., Macêdo J.T.S.A., Araújo, J.A.S., Dantas, A.F.M., Soares, M.P. \& Riet-Correa F. 2008. Ectima contagioso em ovinos e caprinos no semi-árido da Paraíba. Pesq. Vet. Bras. 28:135-139.

Pye D. 1990. Vaccination of sheep with cell culture grown orf virus. Aust. Vet. J. 67:182-188.

Reed L. \& Muench H. 1938. A simple method of estimating fifty percent endpoints. Am. J. Trop. Med. Hyg.18:493-494.

Robinson A.J. \& Balassu T.C. 1981. Contagious pustular dermatitis (orf). Vet. Bull. 51:771-782.

Salles M.W.S., Barros C.S.L., Lemos R.A.A. \& Weiblen R. 1992. Ectima contagioso (Dermatite pustular) dos ovinos. Ciência Rural 22:319-324

Torres S. 1939. Dermatite pustular contagiosa nos caprinos e ovinos no Pernambuco. Bolm Soc. Bras. Med. Vet. 9:107-108. 